\title{
Espacio e imagen del tranvía en la articulación de la ciudad ${ }^{1}$
}

\section{Space and image of the tram in the articulation of the city}

DOI: $10.17981 /$ mod.arq.cuc.18.1.2017.07

Fecha de Envío: 25 de agosto de 2017 Fecha de Aceptación: 27 de octubre de 2017

\author{
Emilio Reyes Schade \\ Universidad de Barcelona (España) \\ emilioreyessch@gmail.com
}

Para citar este artículo:

Reyes, E. (2017). Espacio e imagen del tranvía en la articulación de la ciudad. MODULO ARQUITECTURA-CUC, vol. 18, no. 1, pp. 135-146. DOI: 10.17981/mod.arq.cuc.18.1.2017.07

\begin{abstract}
Resumen
Centrados en la relación entre transporte público y ciudad, el presente artículo persigue profundizar en los aspectos de urbanidad ${ }^{2}$ que los espacios públicos ligados a la infraestructura del tranvía (transporte guiados) pueden conseguir dar a la ciudad. Lo anterior, a partir de la posibilidad de construcción una pauta de articulación, comunicación y (re)estructuración coherente y reconocible que atienda directamente a la idea del espacio público como un sistema polisémico.
\end{abstract}

Palabras claves: Calle, espacio público, imagen de ciudad, transporte público, tranvía, urbanidad.

\section{Abstract}

Focusing on the relationship between public transport and city, this article seeks to deepen the aspects of urbanity that public spaces linked to the infrastructure of the tram (guided transport) can get to give to the city. This, from the possibility of building a pattern of articulation, communication and (re) structuring coherent and recognizable that directly addresses the idea of public space as a polysemic system.

Keywords: Street, public space, city image, public transport, tram, urbanity.

\footnotetext{
${ }^{1}$ Los resultados expuestos son parte de la investigación titulada "El Espacio Público como Interfaz: Tranvía y Metro en Barcelona" desarrollada como parte del Programa de Doctorado Espacio Público y Regeneración Urbana: Arte, Teoría y Conservación de Patrimonio de la Universidad de Barcelona.

2El concepto alude a las "buenas prácticas" o condiciones de calidad del espacio urbano perceptibles por el ciudadano.
} 


\section{INTRODUCCIÓN}

En la organización de la ciudad, la rectificación de las negatividades que ha supuesto el modelo de dispersión en orden a la segregación, fragmentación y homogeneización del territorio nos sitúa en una posición de búsqueda de nuevas ${ }^{3}$ formas de desarrollo más sostenibles y humano.

En este marco de constante incertidumbre es que cobra relevancia la posibilidad de contar con estructuras

${ }^{3}$ Estos Momentos que Cerdà (1867) denomino "salto de umbral" responde al agotamiento de la capacidad de estiramientos de las redes de infraestructura de la ciudad, de forma que lo que existe para cada etapa es un espacio construido (inacabado) que condiciona el futuro crecimiento y transformación de la ciudad. Ante esta realidad la aparición, evolución y/o preponderancia de uno $u$ otro medio de transporte, nos presenta la oportunidad de un nuevo entendimiento hacia dónde direccionar el desarrollo de la ciudad. que nos permitan proyectar con cierta certeza un proceso de transformación y acomodo, que medie y articule simultáneamente las necesidades presentes y futuras con requerimiento locales y globales. En este sentido, es que el binomio espacio público-transporte público a partir de la relación particular que se establece entorno a la inamovilidad de los transportes de tipo guiado le confieren a la ciudad un referente formal, funcional y visual, al tiempo que las reservas de espacio que suponen este tipo de infraestructuras de transporte se proyectan en conjunto a los primeros como agentes o catalizadores de cambio.

En este orden ideas y en coincidencia con los actuales principios de sostenibilidad, la (re)implementación del tranvía

Fig. 1. Esquema de discontinuidad de Av. Diagonal asociado a la implementación del tranvía, Barcelona. Fuente: Ortofoto elaboración propia a partir de Arteaga (2010) e Institut Cartográfic de Catalunya (2005)

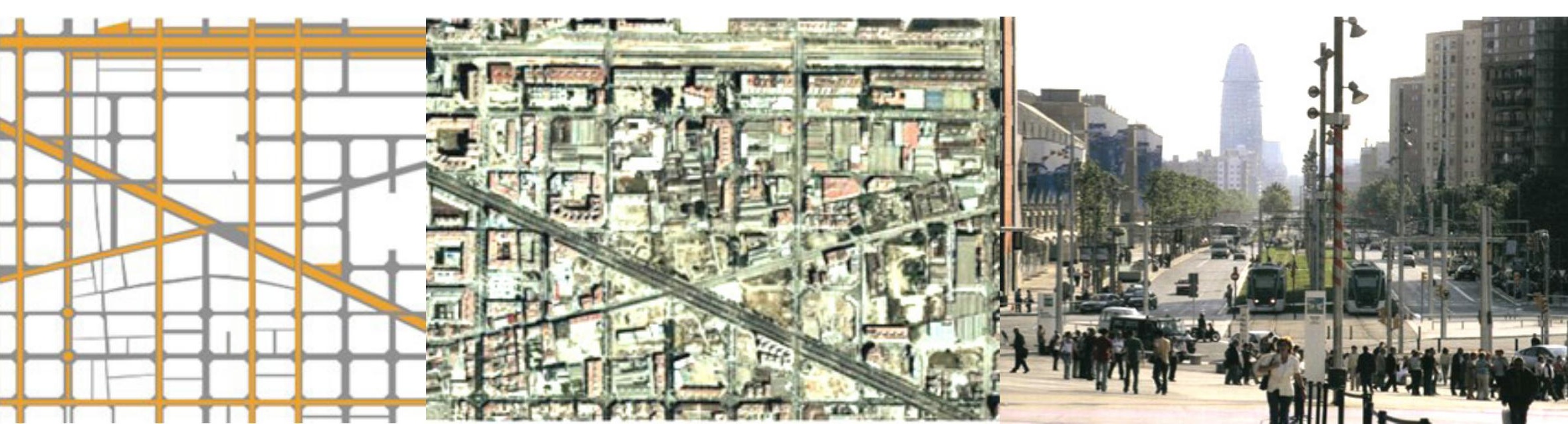


se ha posicionado como una importante pieza de mediación y articulación que ha adquirido el estatus de "pivot organisateur de la trame urbaine et du nouveau paysage généré sur ses bordures" (IPRAUS-ENSAPB ${ }^{4}, 2005$, p. 52)

\section{Tranvía mediación longitudinal}

El trazado del tranvía, a menudo comparado con una columna vertebral, se ha constituido en las últimas décadas en una herramienta, no tan solo eficaz frente a la creciente necesidad de desplazamiento, sino también al surgimiento de

\footnotetext{
${ }^{4}$ Institut Parisien de Recherche: Architecture, Urbanistique, Sociétés-École Nationale Supérieure d'Architecture Paris Belleville
}

nuevas formas de relación al "permet une nouvelle appropriation de la ville" (IPRAUS-ENSAPB, 2005, p. 50). En este sentido, su concepción histórica ${ }^{5}$, su flexibilidad estructural, basada en la diversidad resolutiva que posibilita establecer "diferentes relaciones físicas, espaciales y/o funcionales continuas, discontinuas, puntuales o en red" (Mayorga y Fontana, 2012, p. 125) y su inamovilidad (vínculos duraderos y estables) como factor de estabilidad, le ha posicionado frente a los temas socioespaciales como un importante referente de mediación urbana.

\footnotetext{
${ }^{5}$ El tranvía en la evolución de la ciudad fue un transporte nacido y adaptado a ésta, que introdujo urbanidad tanto al espacio urbano consolidado, como al que se encontraba en consolidación y que mayormente podemos asociar a la periferia.
}

Fig. 1. Esquema de continuidad de Av. Diagonal asociado a la implementación del tranvía, Barcelona Fuente: Ortofoto elaboración propia a partir de Arteaga (2010) e Institut Cartográfic de Catalunya (2005).

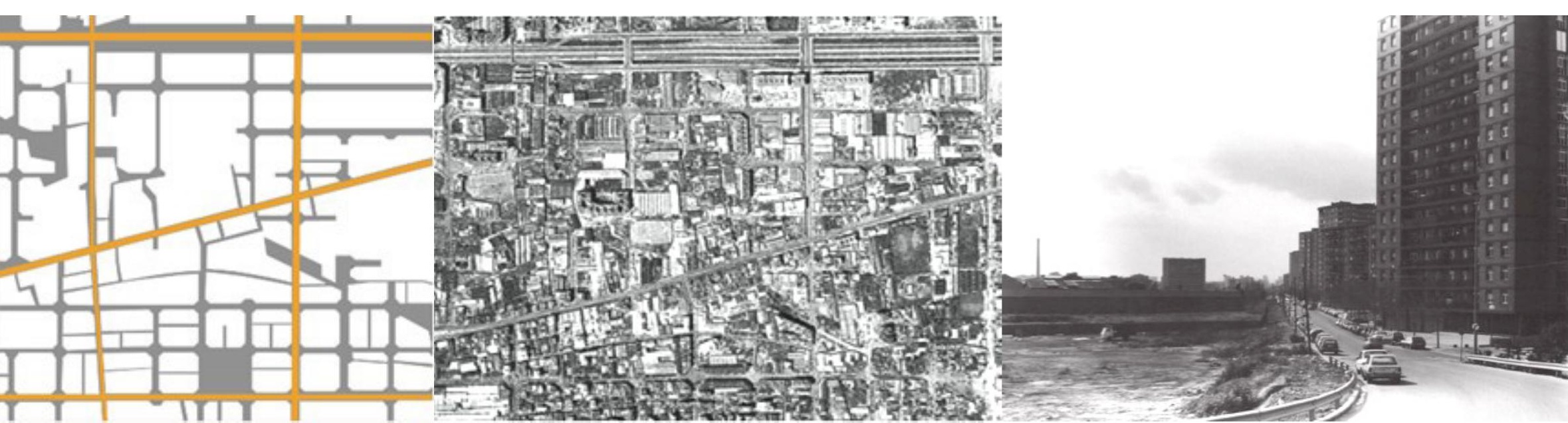


En la línea de lo expuesto y en el marco espacial en el que se ha desenvuelto el tranvía como transporte de capacidad media que conecta y refuerza la competitividad de centralidad mediante un tramo ${ }^{6}$ de comunicación continua complementaria a la infraestructura y/o sistemas significativos de la ciudad de forma que estimula la conducta de viaje multimodal (movilidad cotidiana) y por consecuencia la necesidad de contar con espacios polivalentes que favorezcan la asimilación e interrelación de los diferentes tejidos; al estar su posición de mediación condicionada por la riveraineté $^{7}$ y adhérence ${ }^{8}$ (Brès, 2007), es decir, por el grado de integración urbana de los espacio de la movilidad dentro del espacio urbano.

A partir de los conceptos propuestos y de los actuales estándares de implementación ${ }^{9}$ del tranvía, se puede reconocer que dada la flexibilidad y

\footnotetext{
${ }^{6}$ Sin perjuicio de lo anterior, la sucesión de espacios referenciales, la colmatación y cambio de actividades asociadas a estos tramos, sin llegar a considerarse centralidades, configuran espacios lineales referenciales y significativos para otras centralidades.

${ }_{7}$ Representación del tipo de relación establececido entre la vía o el canal para el movimiento con los bordes de su entorno pudiendo los mismos ser continuos, discontinuos o nulos.

${ }^{8}$ Relación que se establece entre el modo de locomoción y el entorno, y esta puede ser terminal (puntual) o longitudinal (tramos)

${ }^{9}$ Ver Reyes, 2011
}

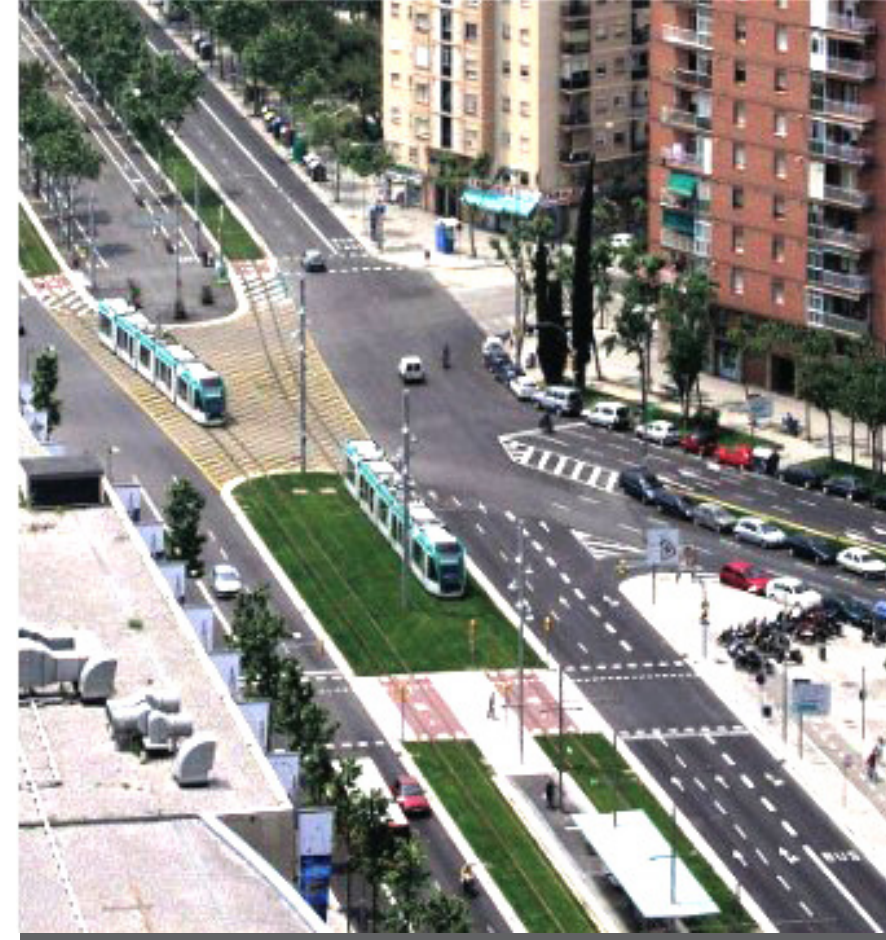

Fig. 2. Algunas resoluciones según el tipo de plataforma: (arriba) plataforma reservada central y (abajo) plataforma compartida. Fuente: elaboración propia.

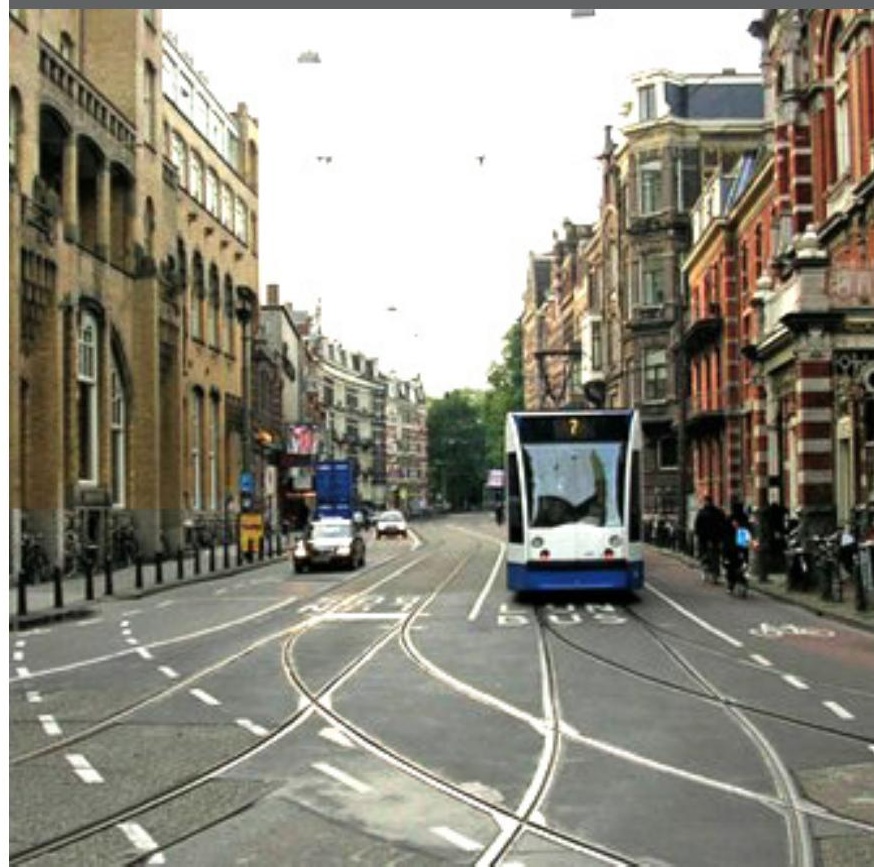


ADHERENCIA DEL MOVIMIENTO

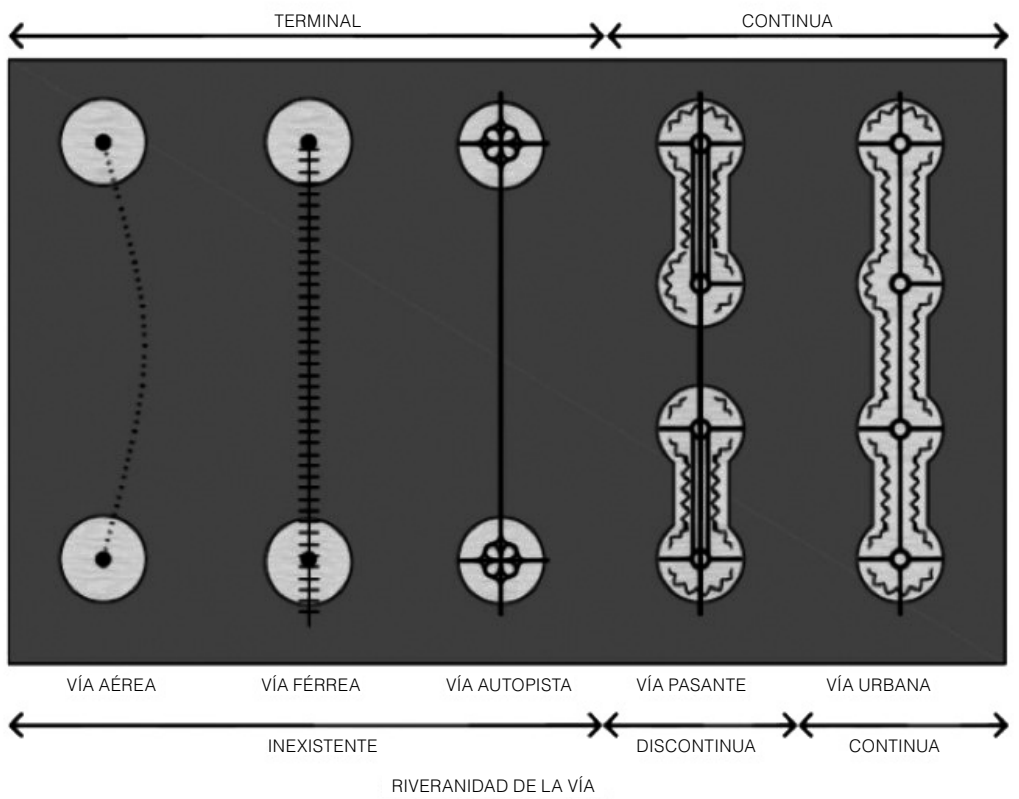

Fig. 3. Grados de riveraineté y adhérence del movimiento según el tipo de vía.

Fuente: Mayorga \& Fontana. 2012, p. 23.

permeabilidad $^{10}$ con el entorno que la relación de riveraineté ha tendido sistemáticamente a la continuidad, se ha favorecido la coexistencia de este medio con los demás usos y actividades presentes en el espacio urbano y la interrelación entre sus tejidos.

${ }^{10}$ Aspectos significativos en esta materia son la equiparación en el reparto del espacio viario (dar cabida a otras funciones urbanas más allá del tránsito), la promoción de la peatonalización y la concordancia que debe existir entre la distancia de las paradas, la sistematización y correlación de los puntos de cruce y su articulación con otros sistemas urbanos.
Así mismo, la relación de adhérence continúa en la que se proyectan los transportes públicos como partes de un sistémica integrado de movilidad sustentado en términos generales en torno a esta permeabilidad y en específico a la posibilidad de acceso a las paradas y los espacios, servicios y/o equipamientos próximos, que posiciona a los primeros como importantes puntos de convergencia y dinamización del entorno. 


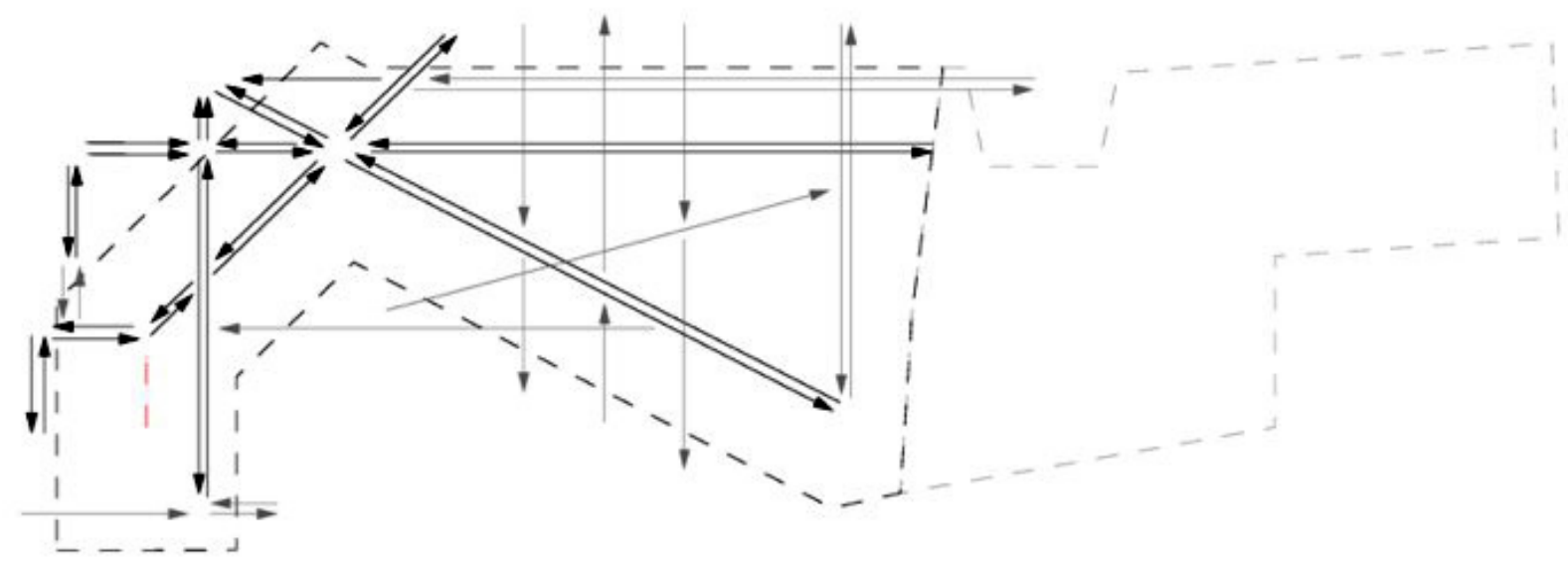

Fig. 4a. Esquema de correlación espacial TramBesòs. Parc de la Ciutadella.

Fuente: elaboración propia.

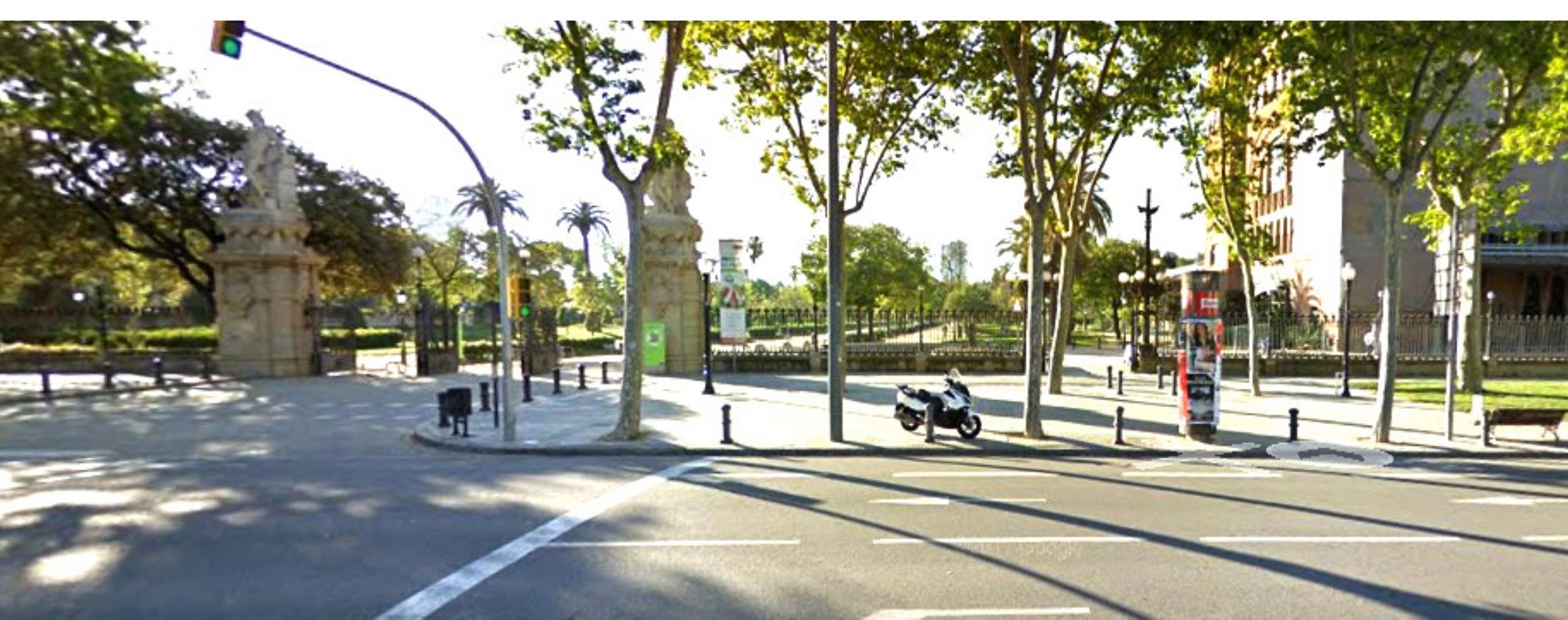




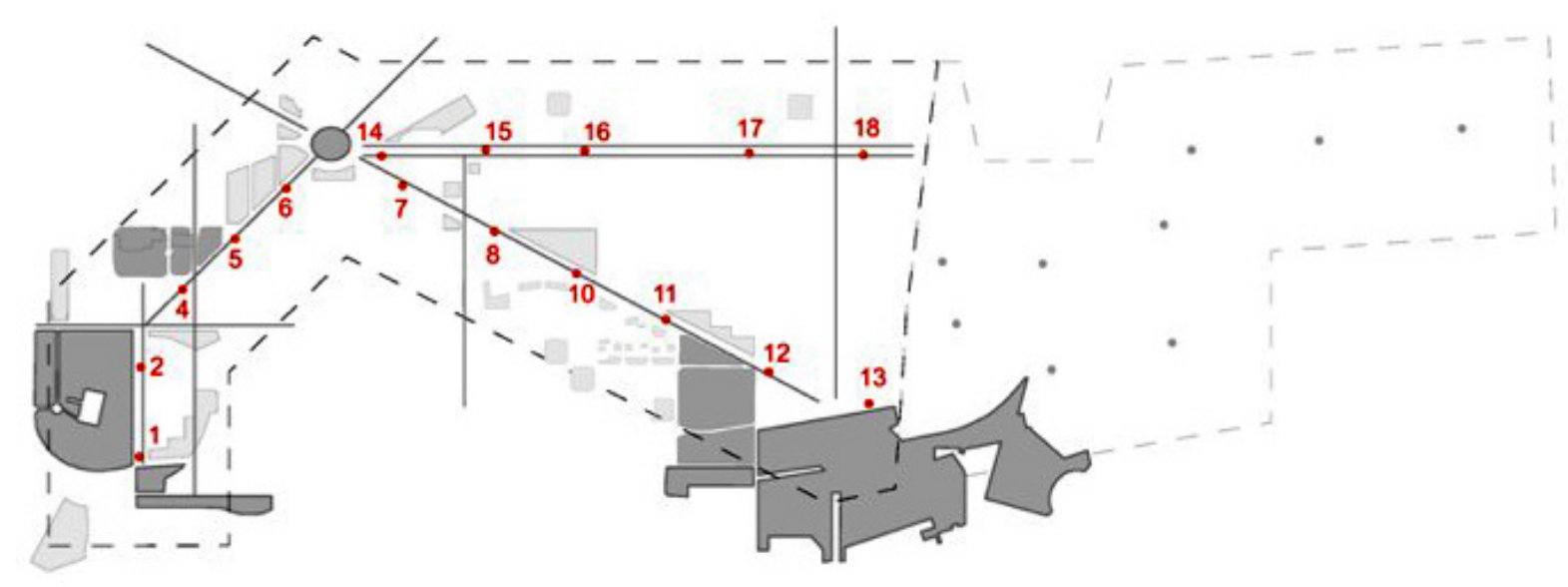

Fig. 4b. Esquema de correlación espacial TramBesòs.

Parc de la Estació del Nord.

Fuente: elaboración propia.

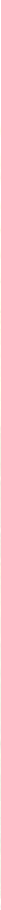




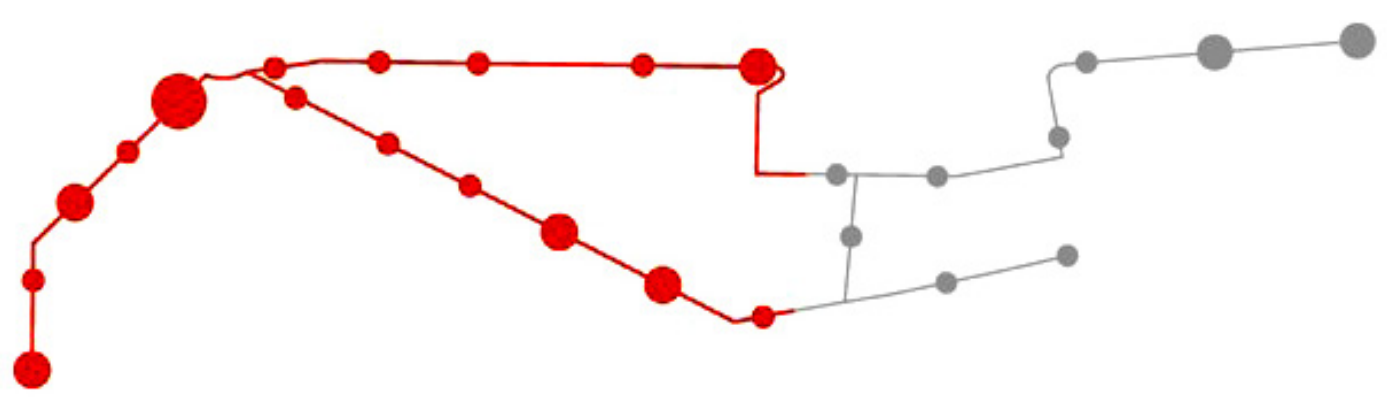

Fig. 4c. Esquema de correlación espacial TramBesòs.

Plaça de les Glòries Catalanes.

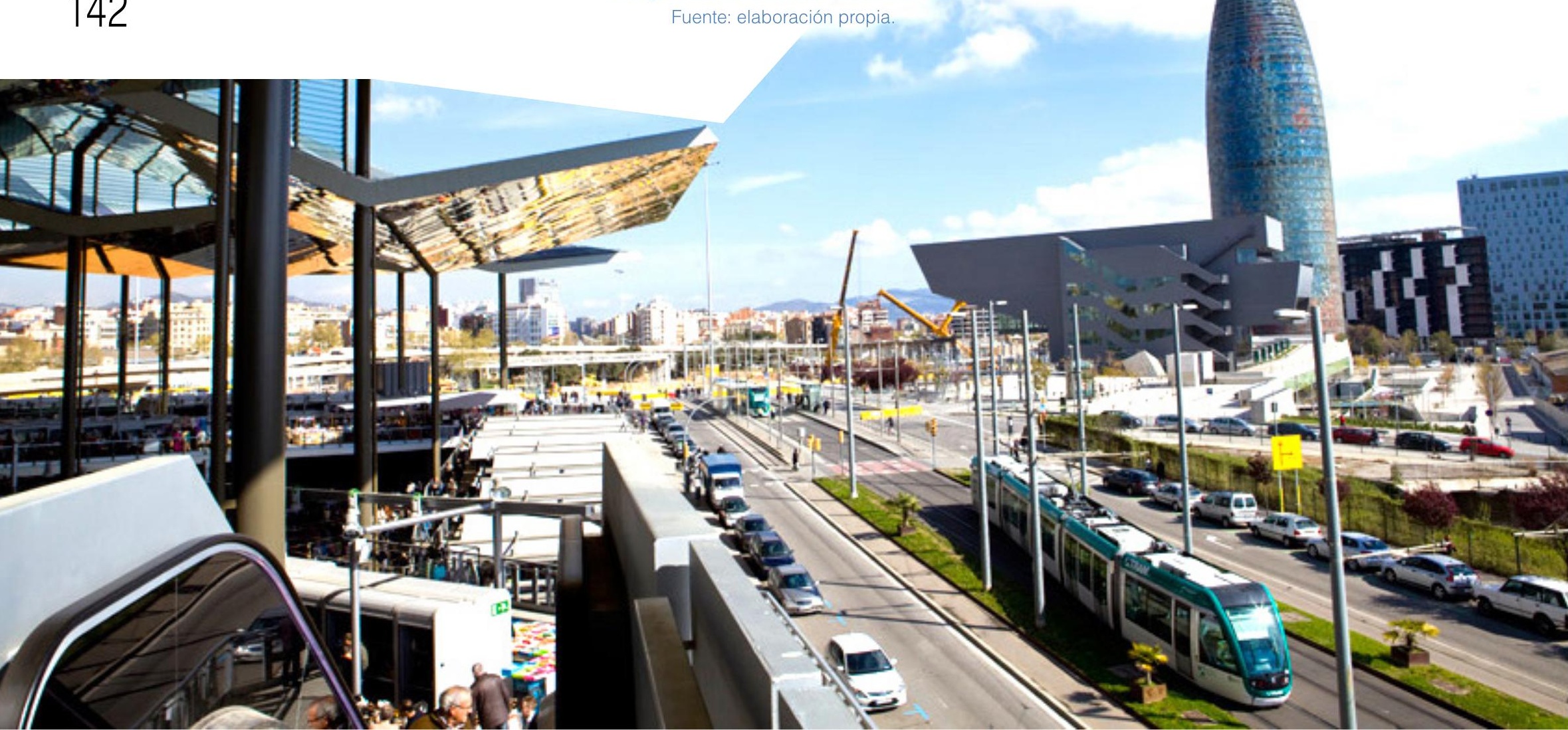




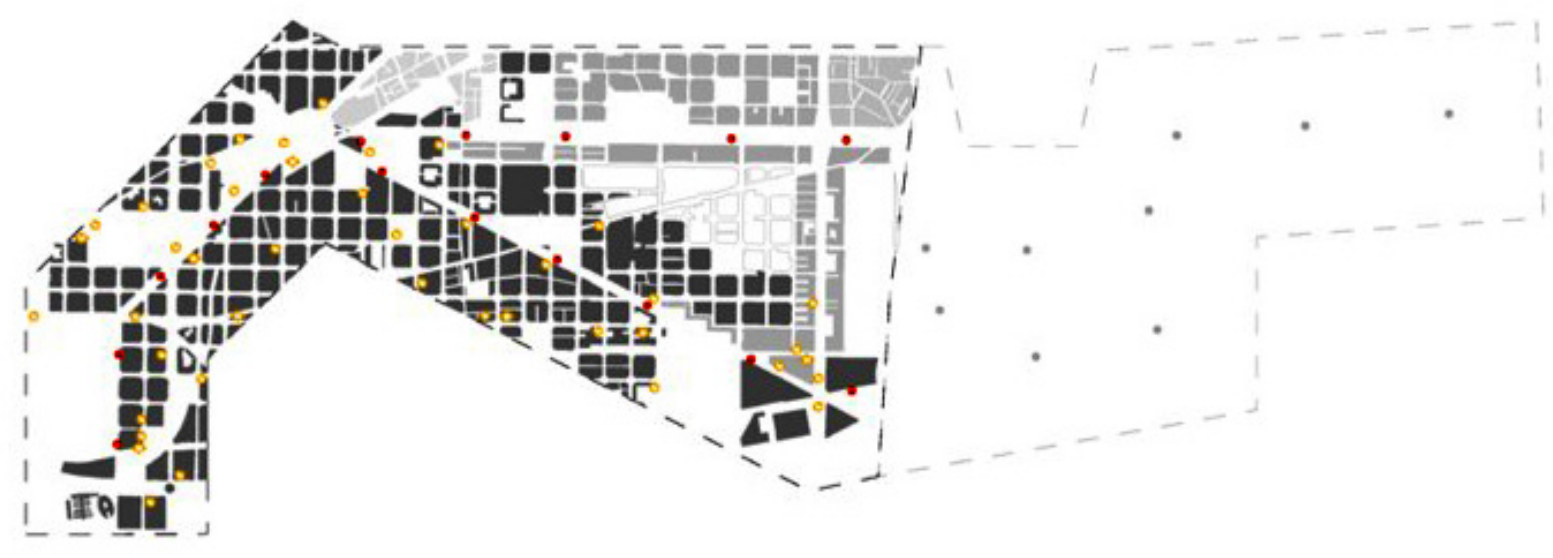

Fig. 4d. Esquema de correlación espacial TramBesòs.

\author{
Parc del Fòrum.
}

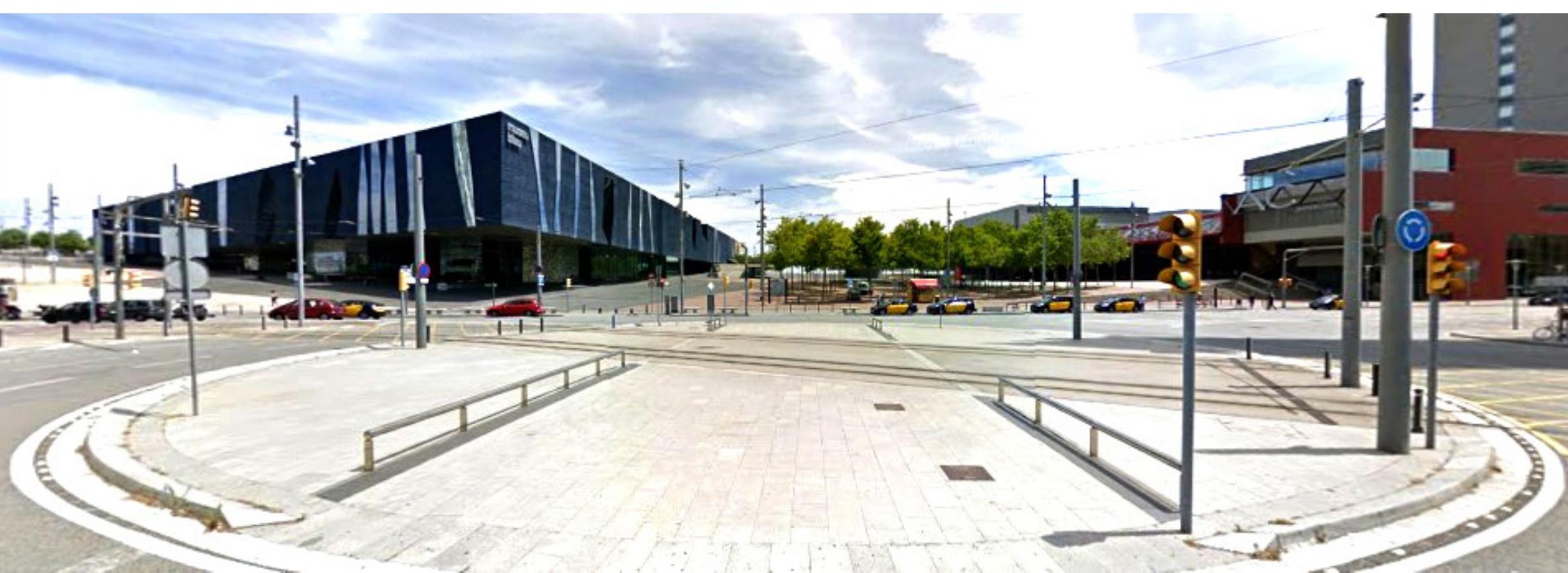


La medicación de estas dos relaciones en términos de la imbricación entre transporte y entorno, condicionan el sentido de urbanidad, dada la promoción de las relaciones transversales a partir de la permeabilidad y accesibilidad longitudinal dentro de un marco espacial específico, la vía, que favorecen la continuidad y la cohesión urbana.

En este sentido, la producción y/o asimilación por cualificación ${ }^{11}$ de espacios no solo se fundamenta o apoya en aspectos visuales, sino, también en aspectos de uso, función y de valoración práctica, que amplían la relación antropológica entre transporte, imagen y lugar.

\footnotetext{
$144 \quad{ }^{11}$ Un factor significativo tiene relación con la incorporación espacio p
}

\section{El Tranvía en la imagen de la ciudad}

En términos de percepción, estructuración y organización del paisaje urbano el tranvía tiene un alto impacto ${ }^{12}$ cómo senda que articula diferentes partes o tejidos de la ciudad mediante una resolución formal, espacial y funcional, común y estandarizada, que extiende y prolonga sus características particulares al entorno, conformando una pieza urbana individualizable, altamente reconocible y enraizada en el tejido ${ }^{13}$ de un área concreta del territorio.

${ }^{12}$ Alto impacto relacionado en gran medida a la inamovilidad de su trazado y a su condición mayormente superficial.

${ }^{13}$ La posibilidad que como pieza urbana pueda ser individualizada no genera disociación de su entorno inmediato, sino más bien la podemos interpretar como un elemento generador de identidad.

Fig. 5a. TramBesòs y TramBaix a su paso por Av. Diagonal. Barcelona, España.

Fuente: elaboración propia.

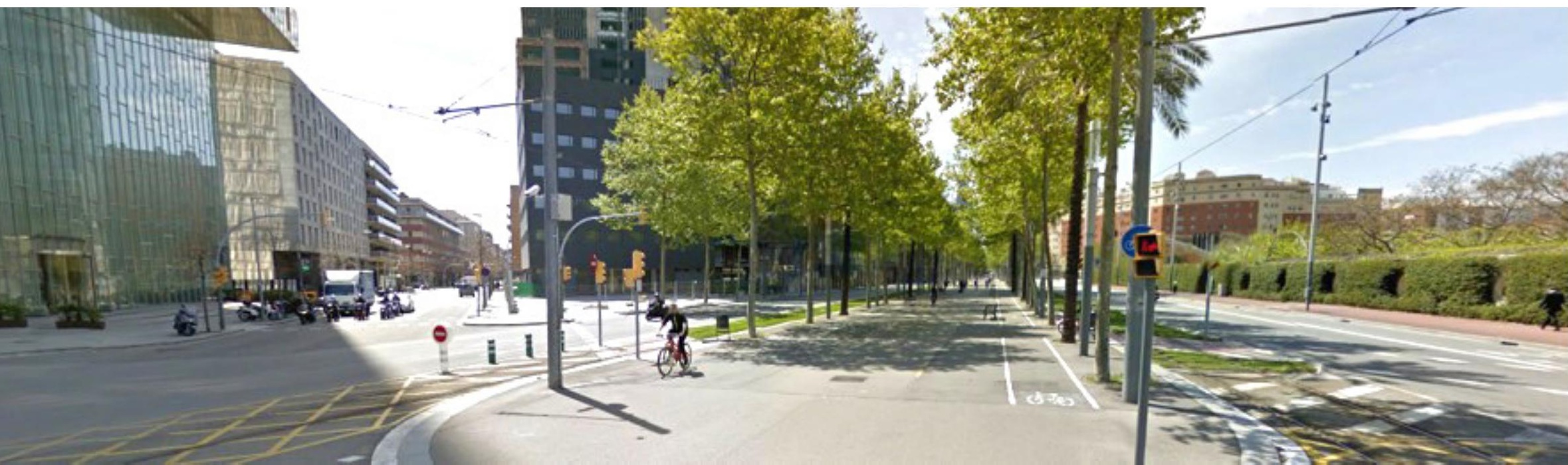


La condición lineal que define su trazado en relación a la disposición viaria y a la incorporación planificada de espacios representativos de la estructura urbana, permite la asociación y concatenación del conjunto de imágenes que generan estos, al tiempo, que el anclaje de esta pieza en el territorio a través de estos espacios es determinante en la configuración de una imagen colectiva que las integra como elementos comunes de organización y orientación, parte de un itinerario cotidiano.

Tomando aleatoriamente diferentes secciones de diferentes trazados, podemos distinguir comparativamente diferencias sustanciales en la definición de la sección del canal del tranvía y en la configuración de la vía. En ambos casos, y aun cuando no comparte una continuidad física podemos reconocer a nivel de percepción, así como también a nivel funcional y programático, un lenguaje común que organiza y unifica las diferencias dentro de una pauta coherente y legible.

La condición de referente visual y funcional que define su papel de articulador entre el conjunto de elementos constitutivos de una imagen mayor, es reflejo de su función vertebrante y estructurante de la ciudad. En este sentido, el trazado del tranvía es significativo para la construcción colectiva de la imagen global de la ciudad al interrelacionar visual y funcionalmente fragmentos (imágenes esporádicas) o partes de la ciudad en el continuo urbano.

Fig. 5b. TramBesòs y TramBaix a su paso por Av. Diagonal. Barcelona, España.

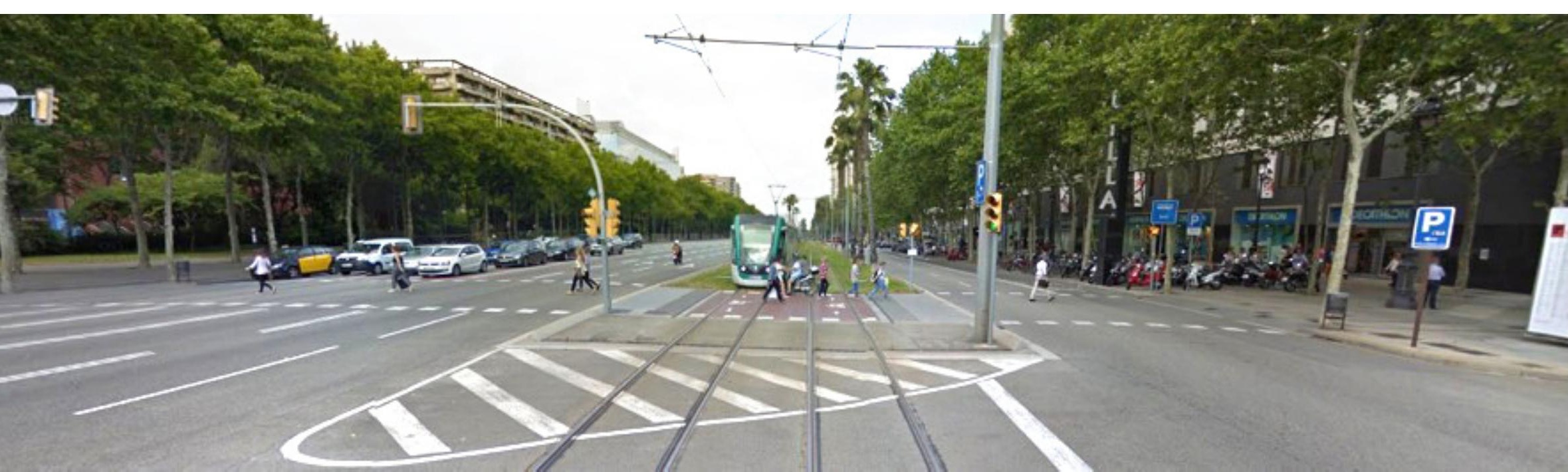




\section{Conclusiones}

La incidencia del tranvía, además de residir en el desempeño que tiene como transporte masivo, la podemos observar en la posibilidad de re-cualificar y pre- figurar la forma y en parte el tipo de desarrollo, convirtiéndose en "le pivot des nouvelles règles de planification territoriale et des projets urbains" (Laisney, 2011); frente a lo cual se ha posicionado como un hito importante en la búsqueda de nuevas formas de crecimiento y/o desarrollo que apuntan hacia una mayor sostenibilidad del medio urbano.

\section{REFERENCIAS}

Arteaga, I. (2010). Construir ciudad en territorios urbanizados transformaciones en la primera periferia. Barcelona: Universitat Politècnica de Catalunya.

Brès, A. (2007). De la voirie: riveraineté et attrition, Des stratégies d'incription territoriale des mobilités périurbaines. La rue entre Réseaux et Territoires. Revista Flux, (66/67).

Cerdà, I. (1867). Teoría General de la Urbanización. Madrid: Imprenta Torroja. Recuperado de http://www.anycerda. org/web/es/arxiu-cerda/fitxa/teoriageneral-de-la-urbanizacion/115
Institut Cartográfic de Catalunya. (2005). Cartoteca Digital. Disponible en http://cartotecadigital.icc.cat

IPRAUS-ENSAPB (2005). Architectures du transport: Rapport final Vol. 3, Tramway, espaces publics et mobilités. Paris: Predit. Recuperado de http://temis.documentation.developpement-durable.gouv.fr/docs/ Temis/0073/Temis-0073796/RMT06002_3A.pdf

Laisney, F. (2011). Atlas des tramways français. Paris: Editions Recherches.

Mayorga, M. y Fontana, M. (2012). Espacios de centralidad urbana y redes de infraestructura. La urbanidad en cuatro proyectos urbanos. Bitácora Urbano Territorial, 21(2). 123-138. Recuperado de http://www.redalyc. org/pdf/748/74826255016.pdf

Reyes, E. (2011). El modelo Barcelona de espacio público y diseño urbano: el espacio público en la inserción del tranvía. El caso del Trambesòs. [Tesis]. Universitat de Barcelona, España. Recuperado de https://issuu.com/ emilioreyessch/docs/el_espacio_p__blico_en_la_inserci_ 